\begin{tabular}{|c|l|}
\hline Title & $\begin{array}{l}\text { A pplication of deep learning techniques for determining the spatial extent and classification of seagrass beds, Trang, } \\
\text { Thailand }\end{array}$ \\
\hline Author(s) & Y amakita, Takehisa; Sodey ama, Fumiaki; Whanpetch, Napakhwan; W atanabe, Kentaro; Nakaoka, Masahiro \\
\hline Citation & $\begin{array}{l}\text { Botanica marina, 62(4), 291-307 } \\
\text { https://doi.org/10.1515/100t-2018-0017 }\end{array}$ \\
\hline Issue Date & 2019-06-12 \\
\hline Doc URL & http://hdl.handle.net/2115/79125 \\
\hline Rights & The final publication is available at www.degruyter.com \\
\hline Type & article \\
\hline File Information & 2019 BotMar Deeplearning Thai seagrass_print.pdf \\
\hline
\end{tabular}

Instructions for use 
Takehisa Yamakita*, Fumiaki Sodeyama, Napakhwan Whanpetch, Kentaro Watanabe and Masahiro Nakaoka

\section{Application of deep learning techniques for determining the spatial extent and classification of seagrass beds, Trang, Thailand}

https://doi.org/10.1515/bot-2018-0017

Received 23 February, 2018; accepted 17 May, 2019

Abstract: Few studies have investigated the long-term temporal dynamics of seagrass beds, especially in Southeast Asia. Remote sensing is one of the best methods for observing these dynamic patterns, and the advent of deep learning technology has led to recent advances in this method. This study examined the feasibility of applying image classification methods to supervised classification and deep learning methods for monitoring seagrass beds. The study site was a relatively natural seagrass bed in Hat Chao Mai National Park, Trang Province, Thailand, for which aerial photographs from the 1970s were available. Although we achieved low accuracy in differentiating among various densities of vegetation coverage, classification related to the presence of seagrass was possible with an accuracy of $80 \%$ or more using both classification methods. Automatic classification of benthic cover using deep learning provided similar or better accuracy than that of the other methods even when grayscale images were used. The results also demonstrate that it is possible

\footnotetext{
*Corresponding author: Takehisa Yamakita, Japan Agency for Marine-Earth Science and Technology, 2-15, Natsushima-cho, Yokosuka-city, Kanagawa 237-0061, Japan; Environmental Dynamics and Management Group, Graduate School of Biosphere Science, Hiroshima University, 1-3-2 Kagamiyama, Higashi-Hiroshima City, Hiroshima 739-8511, Japan; and Division of Global Environmental Studies, Sophia University, 7-1 Kioicho, Chiyoda-ku, Tokyo 102-8554, Japan, e-mail:yamakitat@jamstec.go.jp. https://orcid.org/0000-0002-5451-1231 Fumiaki Sodeyama: Japan Agency for Marine-Earth Science and Technology, 2-15, Natsushima-cho, Yokosuka-city, Kanagawa 237-0061, Japan

Napakhwan Whanpetch: Department of Marine Science, Faculty of Fisheries, Kasetsart University, 50 Ngam Wong Wan Road, Ladyao Chatuchak, Bangkok 10900, Thailand

Kentaro Watanabe: Waterfront Vitalization and Environment Research Foundation, 405, Malissa Hills, 176-4, Asato, Naha, Okinawa 902-0067, Japan
}

Masahiro Nakaoka: Akkeshi Marine Station, Field Science Center for Northern Biosphere, Hokkaido University, Aikappu 1, Akkeshi, Hokkaido 088-1113, Japan. https://orcid.org/0000-0002-5722-3585 to monitor the temporal dynamics of an entire seagrass area, as well as variations within sub-regions, located in close proximity to a river mouth.

Keywords: Andaman Sea; deep learning; land cover classification; long-term dynamics; remote sensing.

\section{Introduction}

Seagrass bed areas are declining worldwide (United Nations 2016), especially in Southeast Asia and Oceania (Waycott et al. 2009, Kawaguchi and Hayashizaki 2011). At local scales, these declines may be caused by direct anthropogenic disturbances, such as eutrophication and land fill, and the indirect effects of land modification, such as sedimentation (Hemminga and Duarte 2000, Short et al. 2018). At large spatial scales, human-induced climate change is another reason for seagrass decline (Orth et al. 2006, Short et al. 2018). The temporal dynamics of seagrass populations are also affected by natural processes such as monsoons, sedimentation, waves, river discharges, and diseases. Natural disasters, such as typhoons, storms caused by monsoons, and tsunamis, can cause large declines in the areas of seagrass beds. Therefore, in order to monitor the remaining seagrass beds for conservation purposes, it is important to understand their natural dynamics, the range of their fluctuations, and their recovery potential by conducting long-term research on natural spatio-temporal fluctuations.

Southeast Asia is a hot-spot of marine biodiversity (Tittensor et al. 2010, Asaad et al. 2017, Yamakita et al. 2017, Faridah-Hanum et al. 2018), including seagrasses. Twenty-four seagrass species have been recorded in the tropical Indo-Pacific bioregion, which extends from the east coast of Africa to the Eastern Pacific (Short et al. 2018). In Thailand, large areas of seagrass beds are distributed throughout the Gulf of Thailand and the Andaman Sea, covering 96.3 and $159.4 \mathrm{~km}^{2}$, respectively (Department of Marine and Coastal Resources, Ministry of Natural Resources and Environment, Thailand 2015). 
Unfortunately, there are few areas in the region where long-term temporal changes of seagrass distribution can be assessed due to limited research (Waycott et al. 2009, Fortes et al. 2018, Yaakub et al. 2018). However, beginning in the 1970s, aerial photographs have been taken of Hat Chao Mai National Park, which is located on the Andaman Sea side of the central Malay Peninsula. This marine reserve has been affected by river discharges, storms, and a tsunami in 2004, and it has been the focus of some research programs (Nakaoka et al. 2007). These conditions make this area suitable for investigating the natural spatio-temporal dynamics of seagrasses.

Several methods can be used to obtain information about the distribution of seagrass. Direct observation by snorkeling, diving, or using a boat is the most basic way. To measure the three-dimensional structure, the use of acoustic sonar is a popular method. Shallow seagrass beds can also be investigated via remote sensing (Komatsu et al. 2002), and aerial photographs and satellite images have been used for this purpose (Wabnitz and Andréfouët 2008, Yamakita et al. 2011). In recent years, unmanned aerial vehicles have become a popular way to observe seagrass beds. Aerial photographs and satellite images have been captured and archived by governmental and/or commercial entities in many areas for the purpose of land management. Using these archived data, it is possible to track long-term changes in seagrass beds to monitor the state and trends of the seagrass as representative of the coastal environment (Dahdouh-Guebas 2002).

When analyzing aerial photographs and satellite images, several methods can be used to interpret land cover and land use (hereafter "benthic cover" in our examples). Visual interpretation by experts can be an accurate way to construct benthic cover maps, particularly when the images are of high spatial resolution. Supervised and unsupervised classification based on the value of each pixel in an image can be performed using remote sensing software packages (Yamakita and Nakaoka 2009). Although these are popular methods for determining benthic cover classifications, they generate small fragments of noise along with correctly classified pixels depending on the condition or resolution of the images. This noise may cause over- or under-estimation of the areal extent and interfere with landscape structure analysis. These methods are also not suitable for grayscale images because there is only a single band available for classifying pixel values.

When images are of higher spatial resolution or grayscale, researchers can use object-based classification (Lyons et al. 2012). Compared to traditional pixel-based methods that use information from each pixel directly for the classification process, the object-based classification method creates aggregations of similarly colored neighboring pixels in the first step of the analysis. Each aggregated area is called an "object" or a "patch" of any land use that is not yet classified. The identified objects are then further classified by a statistical model that uses spectral colors and geometric properties such as size and shape to identify the land use type of each object. Therefore, compared to pixel-color-based supervised and unsupervised classification, object-based classification is more useful for detecting patch structures, especially for images with fine resolution. Object-based classification also achieves better results when using grayscale images, such as old aerial photographs. However, determining thresholds to produce patches, selecting patch properties to be used for classification, and preparing supervised data for each image must be completed manually by experienced experts.

Image-to-image transformation using deep learning techniques was recently developed in the field of computer vision (Isola et al. 2016). This method is expected to enable accurate analysis of images through automated procedures that detect patches and generate image features rapidly. Image-to-image transformation is used to create mathematical mapping from an input image (in this case, the original remote sensing image) to a target image (after benthic cover classification). This transformation model is trained with supervised image data which consist of a pair of input and target images at the learning step. For a new input (test image), the produced model makes it possible to conduct similar transformations by retaining the characteristics of the test images as the model testing step. The deep learning method used in the current study is based on conditional generative adversarial networks (cGAN). cGAN is an image generation technique in which two networks are trained simultaneously: a generator that mimics the target image from a supplied image (supervised data in the model training stage) and a discriminator that distinguishes a fake generated image from one generated from real samples (i.e. the target image). Although the generator and discriminator use a kind of convolutional neural network that is the basic model of deep learning, cGAN shows higher accuracy in image recognition than other conventional machine learning methods, including supervised classification and other simpler deep learning methods (Goodfellow et al. 2016, Creswell et al. 2018, Yamakita 2018, 2019, Yamakita et al. 2018). cGAN was not specifically developed for remote sensing, but the model has been applied to automatic map production from satellite images (Isola et al. 2016). Thus, it should also be applicable to the identification of seagrass beds in remote sensing images. Furthermore, the time and cost required 
for classification are expected to be smaller compared to those of other conventional methods.

This study examined long-term changes in seagrass bed distribution in a marine protected area along the Andaman Sea coast based on remote sensing analyses using aerial photographs and satellite images collected since the 1970s. Our aim was to apply and compare the accuracy of three image classification methods - manual extraction, semiautomatic classification, and deep learning automatic classification - when only grayscale images are available.

\section{Materials and methods}

\section{Study site}

Seagrass beds occur off the coast of Hat Chao Mai National Park, Trang Province, Thailand, on the Andaman Sea side of the Malay Peninsula (Chansang and Poovachiranon 1994, Lewmanomont et al. 1996) (Figure 1). A large series of seagrass beds covering about $6.5 \mathrm{~km}^{2}$ is located along the Andaman coast in the northern part of the marine park between Muk Island and the mainland, named Laem Yong Lam (Lewmanomont et al. 2000, Nakaoka and Supanwanid 2000). The distributions of eight seagrass species [Enhalus acoroides (Linnaeus f.) Royle 1839, Halophila ovalis (R. Brown) J.D. Hooker 1858, Thalassia hemprichii (Ehrenberg) Ascherson 1871, Cymodocea rotundata Ascherson \& Schweinfurth 1870, Cymodocea serrulata
(R. Brown) Ascherson \& Magnus, Halodule uninervis (Forsskål) Ascherson 1882, Halodule pinifolia (Miki) den Hartog 1964, and Syringodium isoetifolium (Ascherson) Dandy 1939] have been recorded in this area.

Although we did not analyze the direct impacts of drivers on seagrass resources, both human impacts, such as coastal infrastructure development, run off from plantations, and aquaculture ponds, and natural disasters like the Indian Ocean tsunami of 2004 can drive spatio-temporal changes in seagrass beds. Some previous studies indicated that the 2004 tsunami had little effect on benthic organisms in this area (Department of Marine and Coastal Resources 2005, Nakaoka et al. 2007).

To describe the seagrass distribution and its patterns of temporal change (also referred to as "temporal dynamics”), the area was divided into nine sub-regions based on depth and geographic features: (1) shallow part of the northern area (Sh-N); (2) river mouth area; (3) shallow part of the middle area (Sh-M); (4) shallow part of the southern area(Sh-S); (5) transition zone of the northern area; (6) transition zone of the middle area; (7) transition zone of the southern area; (8) deeper part of the middle area; and (9) deeper part of the southern area (Figure 1). The classification was first based on water depth, with three depth zones: (1) the coastline to the edge of the intertidal area $(0 \mathrm{~m})$; (2) the slope of the end of tidal flat to subtidal area $(0-2 \mathrm{~m})$; and (3) the deeper area $(>2 \mathrm{~m})$. The tidal effect, transparency of images, and dominant species vary across this depth gradient. The classification was also based on geographic features. A river channel passes

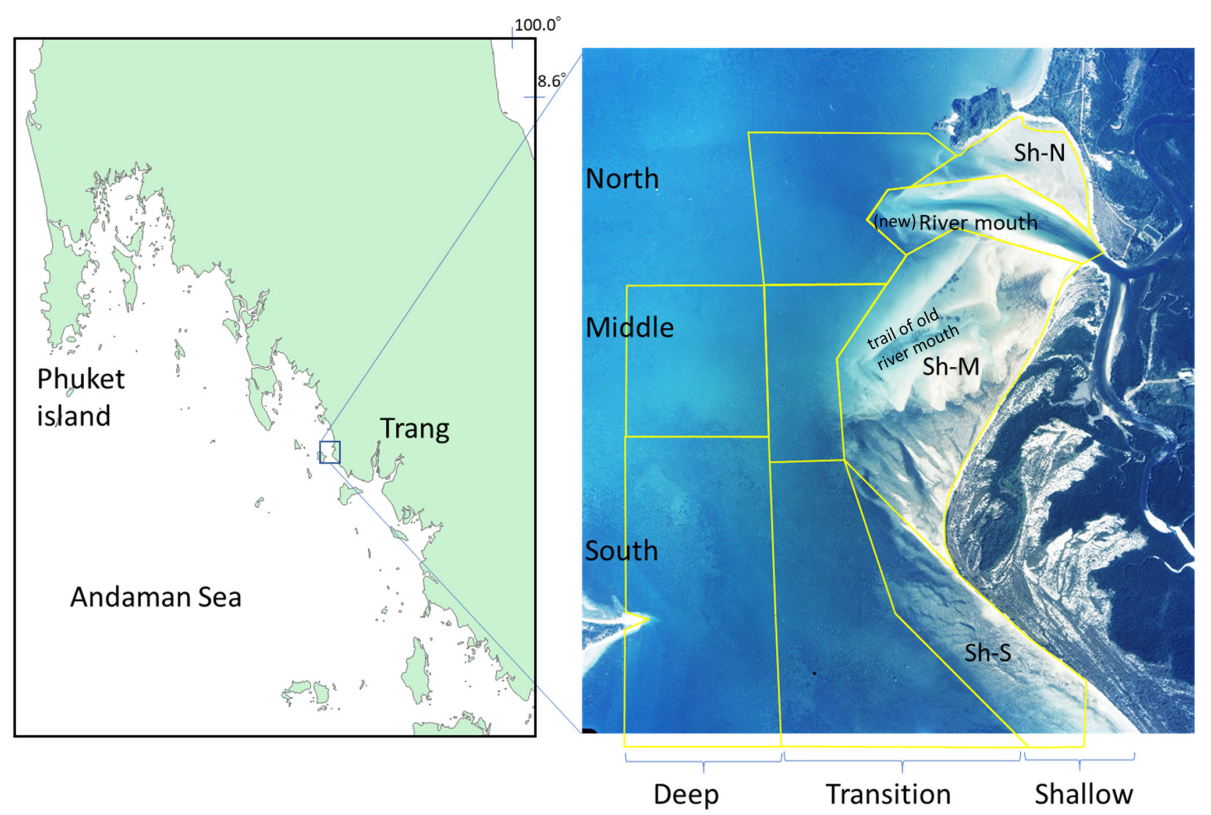

Figure 1: Location of the study site on the coast of Thailand and aerial photograph depicting the outlines of the nine sub-regions. 
through the study area. We refer to the northern side of the river channel as the "northern area," the river channel as the "river mouth," and the southern side of the river channel as the "middle area," each of which is expected to experience different effects of the river. In contrast, the "southern area" is exposed to the open ocean; this area is not affected by the river current, but it is influenced by the coastal current.

\section{Preparation of images}

To conduct image analyses, commercially available satellite images and aerial photographs, which were captured for geographic surveying purposes, were used as data sources (Table 1). For the satellite images, QuickBird orthorectified images captured in 2009 were used. Aerial photographs archived in the Royal Thai Survey Department, spanning 36 years in four periods (1973-1974, 1995, 2003, and 2009) were used. The images were geometrically rectified based on existing rectified aerial photographs, and the total root mean square error after the correction was less than 1 pixel.

From the aerial photographs and satellite images, we extracted three benthic cover types: (1) dense seagrass pixels, with $>70 \%$ coverage; (2) sparse seagrass pixels, with $10-69 \%$ coverage; and (3) sandy areas, with $<10 \%$ coverage. These cover types were classified using four image-analysis techniques: (1) manual extraction based on visual interpretation by an expert; (2) semi-automatic extraction (2a) using pixel-based supervised classification (only for color images) or (2b) using object-based classification (only for grayscale images); and (3) fully automatic extraction using deep learning (for both types of images transformed into grayscale; Table 2). In our analyses, the manually extracted benthic cover was then used as the reference to evaluate the accuracy of the other three image-analysis techniques.

Table 1: List of aerial photographs and one satellite image of Hat Chao Mai National Park, Trang Province, Thailand and their properties.

\begin{tabular}{|c|c|c|c|c|c|c|c|c|c|c|}
\hline \multirow[t]{2}{*}{ Year } & \multirow[t]{2}{*}{ Month } & \multirow[t]{2}{*}{ Day } & \multirow[t]{2}{*}{ Time } & \multirow[t]{2}{*}{ Resolution } & \multirow[t]{2}{*}{ Format } & \multirow[t]{2}{*}{ Height } & \multirow[t]{2}{*}{ Type } & \multirow[t]{2}{*}{ Coverage } & \multicolumn{2}{|l|}{ Analysis method } \\
\hline & & & & & & & & & Semi-automatic & Automatic \\
\hline 1973 & 4 & 17 & $09: 06: 14$ & $0.3 \mathrm{~m}$ & Grayscale & $600 \mathrm{~m}$ & Aerial photo & South & Object based & pix2pix \\
\hline 1974 & 5 & 5 & 08:39:33 & $0.3 \mathrm{~m}$ & Grayscale & $700 \mathrm{~m}$ & Aerial photo & North & Object based & pix2pix \\
\hline 1995 & 1 & 22 & $09: 38: 22$ & $0.3 \mathrm{~m}$ & Grayscale & $480 \mathrm{~m}$ & Aerial photo & South & Object based & pix2pix \\
\hline 1995 & 1 & 29 & $08: 53: 29$ & $0.3 \mathrm{~m}$ & Grayscale & $450 \mathrm{~m}$ & Aerial photo & North & Object based & pix2pix \\
\hline 2003 & 2 & 8 & $10: 48: 13$ & $0.5 \mathrm{~m}$ & RGB & $1700 \mathrm{~m}$ & Aerial photo & Entire area & Pixel based & pix2pix \\
\hline 2009 & 12 & 13 & $10: 49: 50$ & $0.6 \mathrm{~m}$ & $R G B+I R$ & NA & Quick Bird & Entire area & Pixel based & pix2pix \\
\hline
\end{tabular}

Table 2: Images used in the different image-analysis methods of extraction, classification, and accuracy assessment.

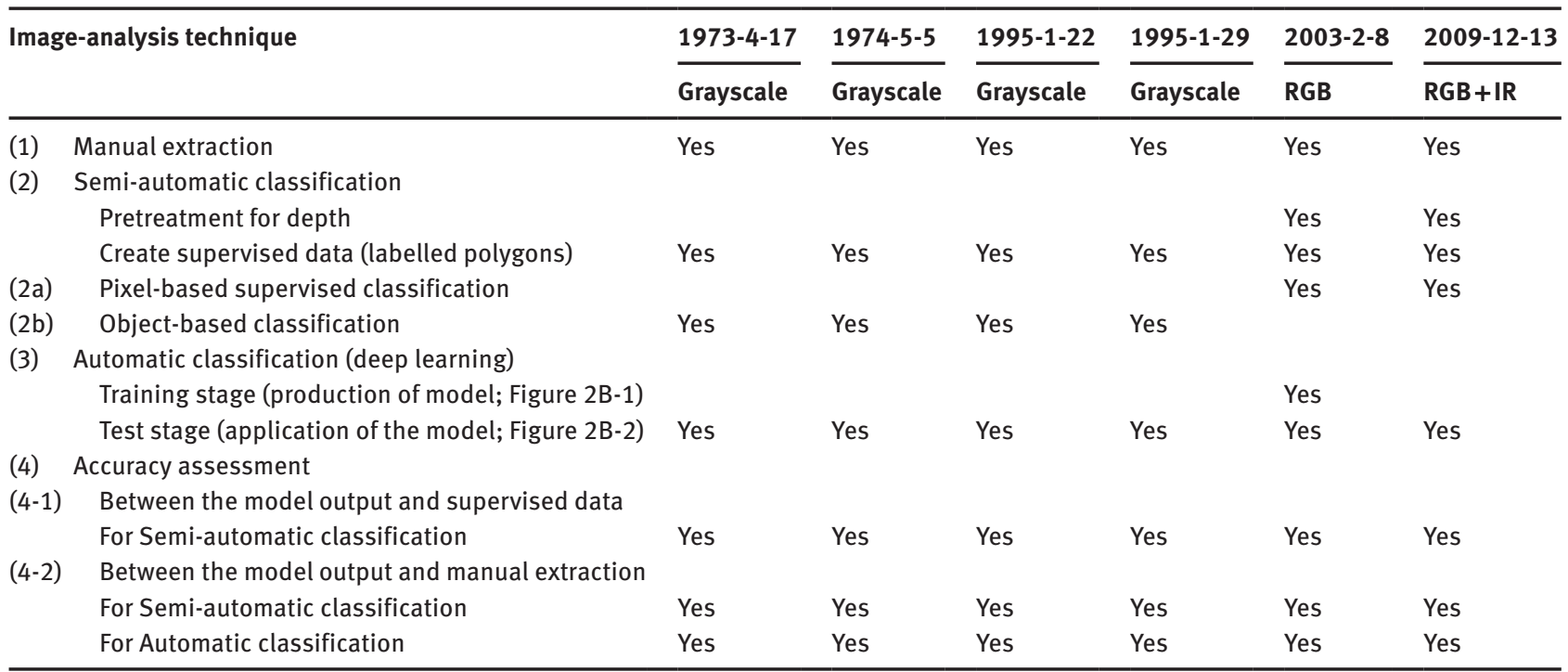




\section{Manual extraction of benthic cover}

For manual extraction, an expert conducted classical visual interpretation and traced the areas of various benthic cover types using a pixel-based tracing tool. To trace patches or pixels of different benthic cover types, raster-based software functions (Photoshop CS6; Adobe Systems Co., Ltd.) were used instead of delineating polygon boundaries by hand using polygon functions in the remote sensing software (Loveland et al. 2000, Campbell and Wynne 2011, Foga et al. 2017, Olthof 2017). Rasterbased tracing enables a more accurate trace of a boundary for the same time investment, but it produces smaller patches of pixels as compared to tracing using handdrawn polygons. Automatic selections based on similar colors in neighboring areas, color range selections, and level correction functions using appropriate thresholds were applied during this process. The extraction took more than $5 \mathrm{~h}$ for each image, including double-checking by experts. During the manual extraction of seagrass distribution, the 2009 aerial photograph was compared to photographs taken by an unmanned airship (Skycatcher, Choryo Sekkei Co. Ltd.) with a Ricoh GR Digital 8-megapixel camera ( $\mathrm{f}=5.9 \mathrm{~mm}$ ) from 50 to $200 \mathrm{~m}$ height between 25 and 27 February 2009. That survey was conducted to obtain high-resolution $(\mathrm{ca} .<10 \mathrm{~cm})$ and highclarity images that enable visual recognition of seagrass.

\section{Pixel-based or object-based semi-automatic classification}

\section{Pretreatment of depth for semi-automatic classification}

Prior to image classification, pretreatment for depth was performed on the RGB color images (Table 2). Watercolumn effects were corrected using the Lyzenga approach to work with benthic albedo as opposed to water-column reflectance + benthic albedo signals (Lyzenga 1978, 1981, Matsunaga et al. 2000). For more than 20 polygons that were distributed across the whole area and contained sufficient numbers and combinations of pixel colors to create a regression model, RGB-band values for the sandy areas were extracted. For the RGB color images, an index of bottom type for each band combination was constructed using the band ratio rectified by the extinction coefficient (Lyzenga 1978, 1981, Matsunaga et al. 2000). The extinction coefficient of each band pair was estimated using the slope of the linear regression of the band-to-band scatter plot. Pixel values in the sandy areas for each band combination were used for this estimation.

\section{Creating supervised data for semi-automatic classification}

Supervised data for semi-automatic classifications were independently created based on classic manually traced data of the seagrass and sandy areas. Locations clearly recognizable as seagrass or sandy areas based on the levelcorrected images were hand-traced using GIS polygons. The polygons were also labelled based on the same criteria of the manual extraction of vegetation coverage assuming an approximate projection coverage: dense coverage (70-100\%), sparse coverage $(10-69 \%)$, or no seagrass $(0-10 \%)$ pixels. These data were created by the authors, who have conducted field surveys of this area and have experience with remote sensing of seagrass beds; it took us no more than $1 \mathrm{~h}$ for each image. Reference images for the extraction of seagrass areas in the most recent photographs were obtained during field observations between 6 and 10 March 2008, and the result of this trace was double (cross)-checked by the interpreters.

\section{Pixel-based or object-based semi-automatic classification}

For the semi-automatic benthic cover type classification process, supervised classification based on maximum likelihood of the band-ratio combinations of RGB color images was conducted using the Geographic Resources Analysis Support System (GRASS) GIS ver. 7.2.1 (GRASS Development Team) and Spatial Analyst of Arc GIS ver. 10.2-10.3 (ESRI Inc.). For the grayscale images, objectbased image classification was conducted by using the GRASS GIS and regression analysis decision tree (CART) in $\mathrm{R}$ ver. 3.4.1 ( $\mathrm{R}$ Development Core Team). These data were also pre- and post-processed by using standardized methods such as rectification using polynomial correction and masking of the terrestrial area using GRASS GIS, Quantum GIS ver. 2.14 (Quantum GIS Development Team), and Arc GIS ver. 10.2-10.3 (ESRI Inc.).

\section{Automatic classification using deep learning}

Using manually classified data of the 2003 aerial photograph as a training dataset, image-to-image transformation was conducted using pix2pix, which is based on a general-purpose cGAN framework (Isola et al. 2016, Beckham and Pal 2017). A GAN is an image generator model that enables transformation from an input image to an output image that mimics a target image (Figure 2A). 
A Basic structure of the model training

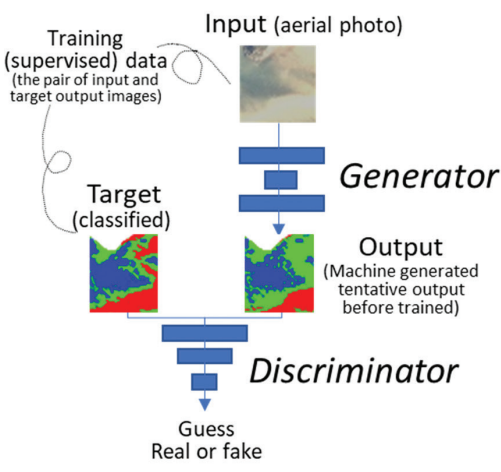

B Flow of the analysis

B-1 Training stage

(build the model using training data i.e an aerial photograph and manually classified 2003 image)

Sliced into $128-\mathrm{m}$ grids transformed into grayscale

Selected pairs of images (feed to the pix2pix)
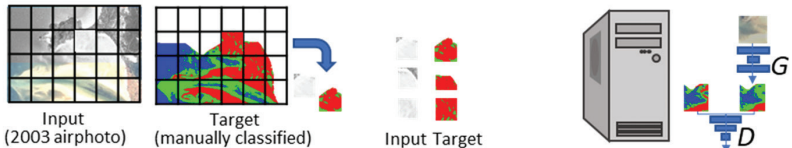

B-2 Test stage

(classify the new input images i.e aerial photographs of other years)

Sliced into 128 -m grids

transformed into grayscale
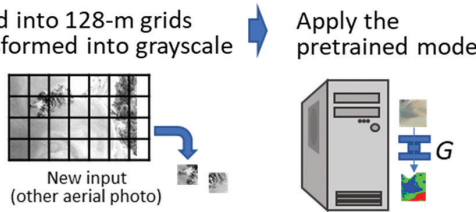

Merged into the original position of the aerial photograph

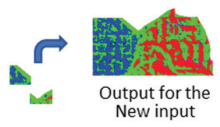

Figure 2: Graphical abstract of the analyses of the aerial images using pix2pix.

(A) Basic structure of conditional generative adversarial networks (cGAN) model training used in pix 2pix. To train the model, the competition between the generator and discriminator was repeatedly conducted until the generator was trained by the discriminator to create outputs indistinguishable from the target. (B) Flow of the analyses showing pre- and post-processing for model training using supervised data in the model.

The transformation model was developed using automatic learning of a loss function to achieve the goal of "making the output indistinguishable from reality." In this case, reality indicated the target (classified) image in the training (supervised) data (based on comparison of the model output and target images). The goal was achieved via reinforcement learning between two types of neural networks (i.e. the application of convolutional neural networks), which can automatically learn features of an image. One neural network is the generator that creates machine-generated tentative outputs, which are intended to mimic the target of the supervised data using features learned by the neural network. The other is the discriminator that distinguishes between a real image (the target in the training) and a generated image (the machine-generated tentative output). Pix2pix is a pre-coordinated framework that uses a conditional GAN, which considers pairs of images (input and target) as a condition to create the model. In pix2pix, specialized network structures, rather than the standard convolutional neural networks (Isola et al. 2016), were applied to both the generator and the discriminator to maintain the characteristics of the input images.

\section{Training stage of automatic classification}

For training data, a combination of the grayscale transformed aerial photograph taken in 2003 and the manually classified results of the color image taken in 2003 were used (Figure 2B-1); among the aerial photographs, the
2003 photo provided a relatively clear view and highly confident classification results. The data were sliced into 128 -m grids $(256 \times 256$ pixels $)$ to fit the framework of pix2pix, which is optimized for this image size. From the grid data, 1169 pairs of images that accurately classified the benthic cover types with little noise were selected as the training data to feed to pix2pix. At this point, most of the areas depicting sunlight contamination (halation) in the deeper part were eliminated. Then pix2pix was run to train the model (generator) by using the default setting.

\section{Test stage of automatic classification}

To produce classified images in the test stage (Figure 2B-2), the aerial photographs were sliced for application to the pre-trained model. Each color photograph was transformed into grayscale to apply the same pre-trained model for all the aerial photographs. The results of the transformation for each grid were merged into the original position of the aerial photograph.

\section{Interpretation of results and accuracy assessment}

Three types of seagrass distribution maps were obtained from each image, by using (1) manual extraction; (2) semiautomatic classification (either supervised classification for color images or object classification for grayscale 
images); and (3) automatic classification (Table 2). Temporal changes in the spatial extent and distribution of the extracted locations of seagrass beds in each sub-region, with particular focus on the three shallow sub-regions, were assessed.

To verify the classification model using the supervised data ("model verification" hereafter; Table 2, technique 4-1), the supervised and object-oriented semi-automatic classifications and the training data were compared based on the overall accuracy of the classification (\% correctly classified) and Cohen's $\kappa$ statistic, an index of inter-raster agreement. The $\kappa$ value indicates agreement without random coincidence; in general, a value $>0.4$ is moderate agreement, $>0.6$ is substantial agreement, and $>0.8$ is almost perfect agreement (Landis and Koch 1977). To evaluate the accuracy of each benthic cover class, omission and commission errors and the bias (ratio) of these two types of errors were generated. An omission error indicates the rate of incorrect classification when compared to a class in the reference (true) data (each class in the reference is the denominator). It is also known as 1 - sensitivity or false negative rate and is equivalent to a Type II error. A commission error indicates the rate of disagreement of the reference data to a class of the classification result (each classified class is the denominator). It also called a 1 - precision or false discovery rate.

The classification results (i.e. semi-automatic classifications plus automatic classification using image transformation) were also compared with the results of the manual extraction ("result verification" hereafter; Table 2, technique 4-2). More than 2000 random reference points were plotted in the survey region and compared with the majority of benthic cover types within a 5-m buffer. Together with the previously mentioned indices of accuracy, the variation of estimated vegetation coverage in each sub-region was also assessed for accuracy.

To interpret the results, temporal changes in the manually extracted results were compared with those obtained by using the other methods. Visual interpretation of the aerial photographs was also compared among classification methods, including manual extraction.

\section{Results}

\section{Comparing the accuracy of the classification methods}

The results of the classifications are presented in Figure $3 \mathrm{~B}-\mathrm{D}$, and the results of the two types of verification are listed in Table 3. The accuracy measures determined by comparison with the supervised data (model verification) varied depending on the year, depth, and analysis method. The overall accuracy of the semi-automatic classifications was $72 \% \pm 14 \%$ (mean \pm SD), with $\kappa=0.54 \pm 0.24$. The accuracy was lower for the older grayscale images $(65 \% \pm 9.11 \%$, $\kappa=0.42 \pm 0.16)$ and higher for the two newer color images $(87 \% \pm 7 \%, \kappa=0.80 \pm 0.10)$. The average omission and commission errors for each benthic cover type were high in the grayscale images, especially for sand and sparse vegetation; the omission errors were $0.46 \pm 0.10$ (sand) and $0.44 \pm 0.23$ (sparse) and the commission errors were $0.68 \pm 0.13$ (sand) and $0.36 \pm 0.18$ (sparse). The underestimation of sand area was also explained by a bias toward commission. These errors were low for the color images; the omission errors were $0.07 \pm 0.01$ (sand) and $0.20 \pm 0.20$ (sparse) and the commission errors were $0.07 \pm 0.02$ (sand) and $0.16 \pm 0.11$ (sparse). Although the constructed semiautomatic classification models were of a reasonably good level in the color images, lower accuracies in the model construction were observed in the grayscale images in most cases.

When the overall accuracy was determined based on a comparison with independently manually extracted results (result verification), these values were $55 \% \pm 16 \%$ $(\kappa=0.28 \pm 0.17)$ for semi-automatic classification and $63 \% \pm 4 \%(\kappa=0.35 \pm 0.07)$ for automatic classification using deep learning (Table 3). Except for the image taken in 1974, automatic classification provided higher accuracy. Comparing the older and newer types of images, the accuracy was $50 \% \pm 18 \%(\kappa=0.30 \pm 0.17)$ (semi-automatic) and $61 \% \pm 1 \%(\kappa=0.35 \pm 0.77)$ (automatic) for the older grayscale images and $64 \% \pm 2 \%(\kappa=0.37 \pm 0.03)$ (semiautomatic) and $67 \% \pm 3 \%(\kappa=0.36 \pm 0.08)$ (automatic) for the two newer images. The differences in the accuracy observed between newer types and older types of images were almost half for the automatic classification in comparison with the semi-automatic classification. The accuracy values were lower by $15 \%$ as compared to the results of the model verification in the case of the semiautomatic classification. In the case of image 1995-01-22, the overall accuracy was very low and failed to predict the benthic cover while using semi-automatic classification, which was not the case using automatic classification. Average omission and commission errors for this image were also high, especially for sand and sparse vegetation: $0.53 \pm 0.29$ (omission) and $0.58 \pm 0.17$ (commission) for sand and $0.51 \pm 0.18$ (omission) and $0.67 \pm 0.13$ (commission) for sparse beds in all semi-automatically classified images. For the automatically classified images, they were also high for the same categories: $0.52 \pm 0.16$ (omission) 
1973 and 1974

1995

2003

2009

A Rectified images
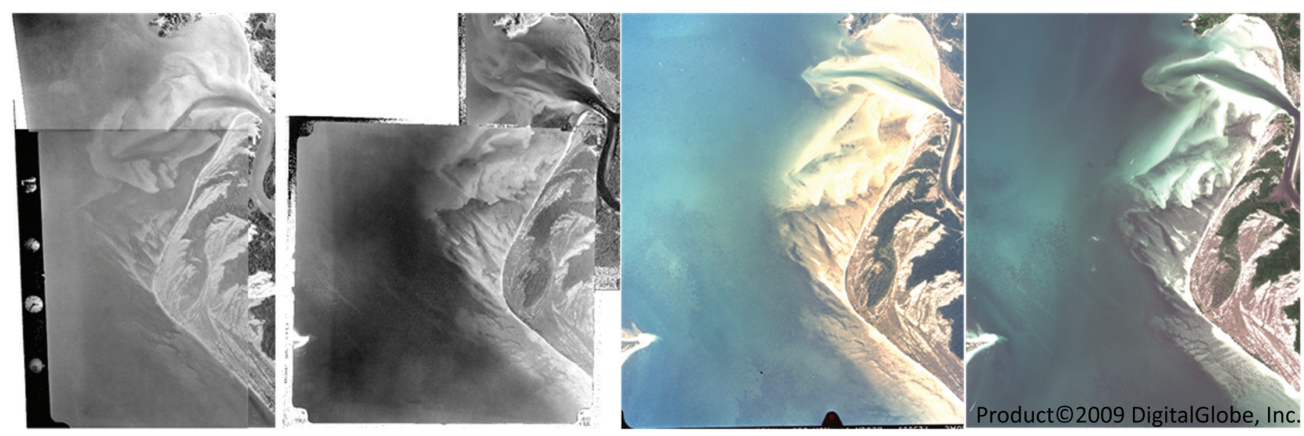

B Manually extracted images
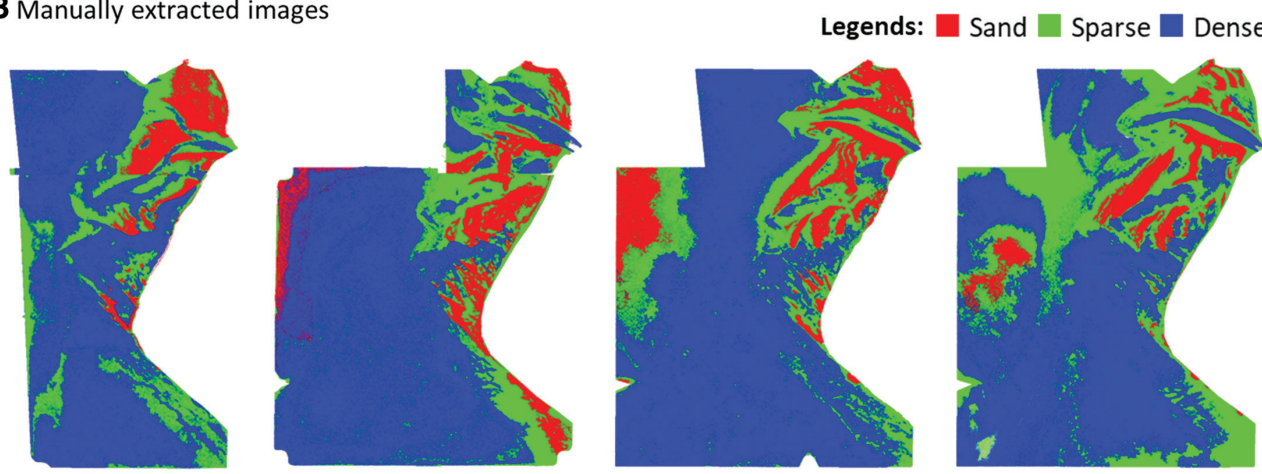

C Semi-automatically classified images

Legends: $\square$ Sand $\square$ Sparse $\square$ Dense
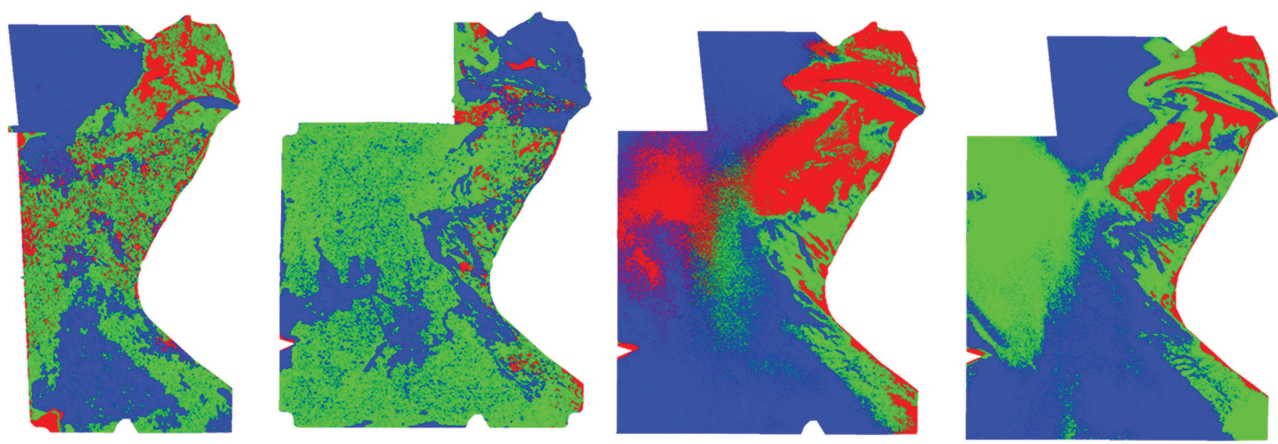

D Automatically classified images using deep learning from gray images
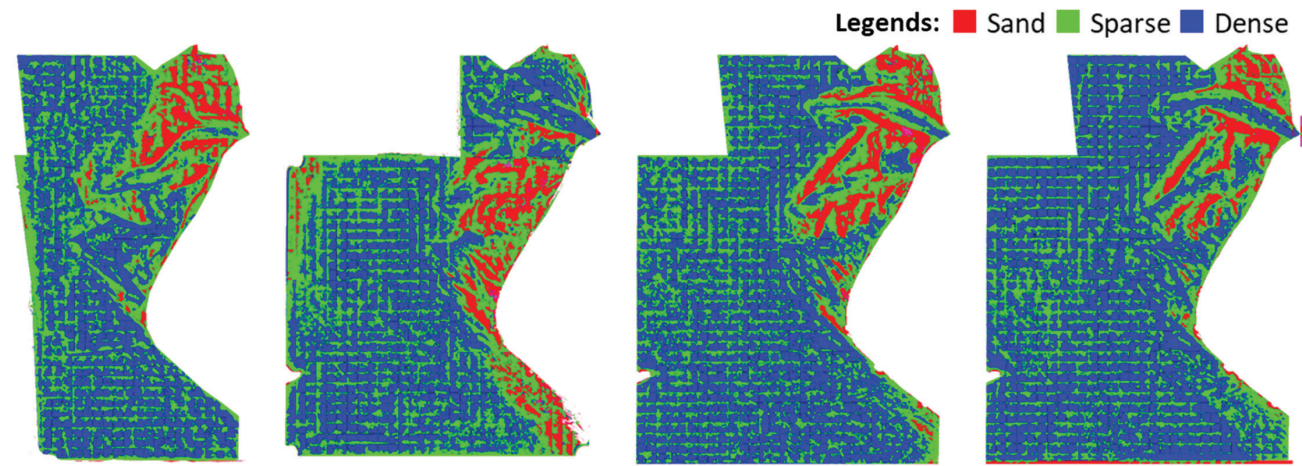

Figure 3: (A) Rectified images of the study area taken in 1973-1974, 1995, 2003, and 2009. Areas of sand, dense seagrass, and sparse seagrass classified based on (B) manual extraction, (C) semi-automatic classification, and (D) automatic classification, using deep learning from grayscale images.

Original images from 1973 to 2003 taken by Royal Thai Survey Department. Images for 2009 include derivative of copyrighted material of DigitalGlobe, Inc., All Rights Reserved. 


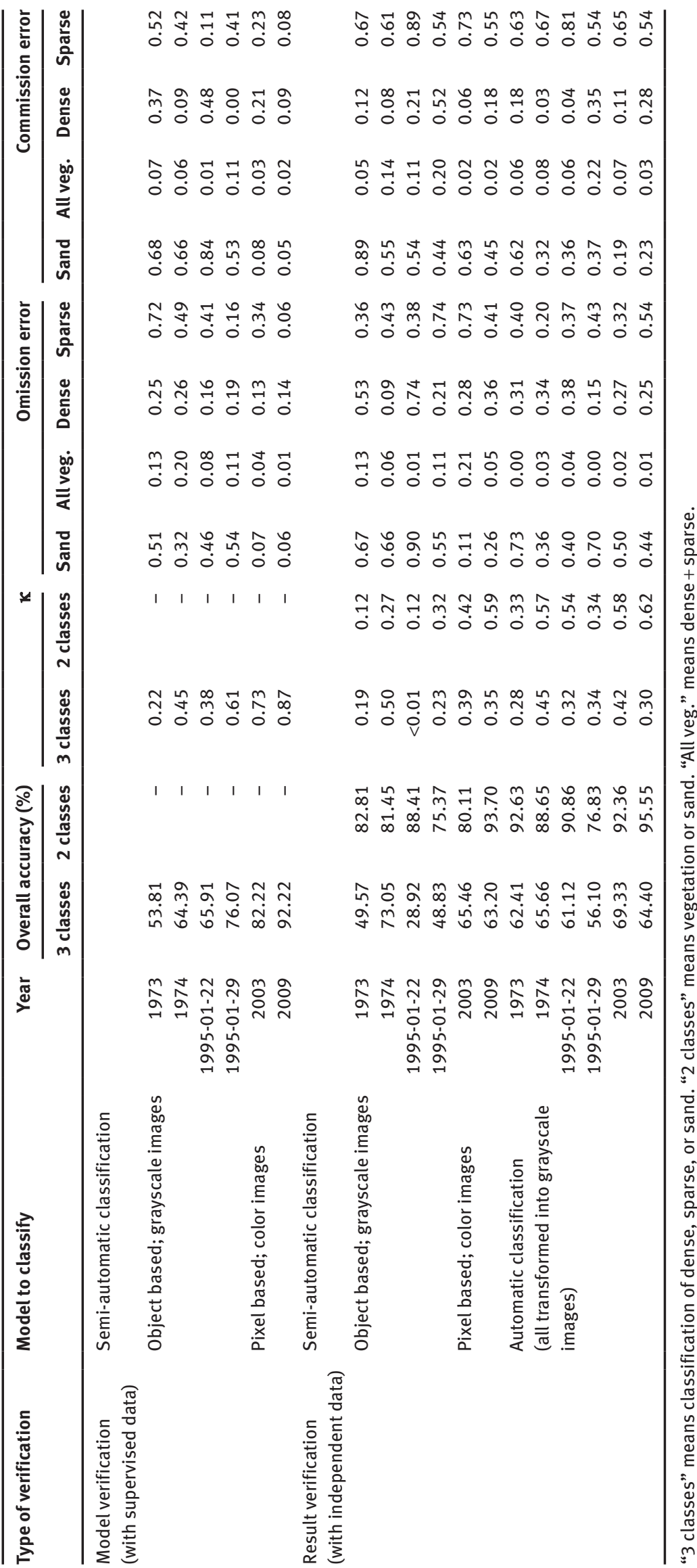


and $0.35 \pm 0.15$ (commission) for sand and $0.38 \pm 0.12$ (omission) and $0.64 \pm 0.10$ (commission) for sparse beds. The higher bias toward commission error at sparse beds in the automatic classification reflects overestimation of this category, especially in the offshore area. Because the errors for sand were not easily distinguished from errors caused by sunlight contamination in the offshore areas, classification errors in the sparse beds were only reduced by combining the two categories of seagrass coverage.

The overall accuracy increased considerably when the two seagrass coverage categories were combined into a single category of seagrass presence or absence; the accuracy increased to $84 \% \pm 6 \% \quad(\kappa=0.31 \pm 0.18)$ for the semi-automatic classification and to $89 \% \pm 7 \%$ $(\kappa=0.50 \pm 0.13)$ for the automatic classification. For the grayscale images, it was $82 \% \pm 5 \%(\kappa=0.21 \pm 0.10)$ (semiautomatic) and $87 \% \pm 7 \%(\kappa=0.45 \pm 0.13)$ (automatic). For the color images, it was $87 \% \pm 10 \%(\kappa=0.51 \pm 0.12)$ and $94 \% \pm 2 \%(\kappa=0.60 \pm 0.03)$. The average omission and commission errors for all types of vegetation (combined dense and sparse) were low: $0.08 \pm 0.05$ (omission) and $0.12 \pm 0.06$ (commission) for semi-automatic classification and $0.02 \pm 0.02$ (omission) and $0.10 \pm 0.08$ (commission) for automatic classification of the older grayscale images. They were $0.13 \pm 0.12$ (omission) and $0.02 \pm<0.01$ (commission) and $0.01 \pm<0.01$ (omission) and $0.05 \pm 0.02$ (commission), respectively, for the two newer images.

Considering the spatial structures of the classified patches (Figure 3) in the large-scale versions of the 1995 image, there were clear discontinuities at the edges of the original aerial photograph because of the semi-automatic classification. This artifact was caused by limb darkening of the lens, the angle of sunlight, and atmospheric conditions. This discontinuity was observed less for the automatic classification.

Although the automatic classification depicted better results at larger scales, in general, it sometimes failed to discriminate patches in small areas of the images. These areas of failed discrimination were visually identified as a mixture of noise-like pixels of some categories, especially in areas of dense vegetation (see the deeper part of Figure 3D). In such cases, the grid boundaries were clearly discontinuous and were observed as artificial noise in the resulting images.

\section{Comparison of the temporal dynamics}

We compared seagrass areas (presence or absence) between the manually extracted (reference) images and the classification results (Table 4). Semi-automatic classification resulted in $-5.2 \pm 23.6$ ha difference (i.e. underestimation) and automatic classification resulted in $4.6 \pm 12.1$ ha overestimation. Even after eliminating the results using training data (2003), the variance was smaller in the automatic classification; for each dense and sparse vegetation area, the difference was $-24.9 \pm 46.4$ and $21.2 \pm 48.6$ ha, respectively, for the semi-automatic classification and $-14.1 \pm 31.5$ and $19.6 \pm 29.5$ ha for the automatic classification. Thus, the direction (+ or -) of misclassifications was similar for both methods.

We next assessed the overall changes in the spatial extents of the seagrass beds. Based on the manually extracted data, the mean area of all types of vegetation in the study area was $1230 \pm 201$ ha (in Table 4 "Total area full extent" which contains areas not covered by some aerial images i.e. no data for the deeper area during 19731974 and the 1995 northern transition zone). This result was similar to those of the other methods: $1184 \pm 195$ ha for the semi-automatic classification and $1271 \pm 201$ ha for the automatic classification. Of this vegetation, $878 \pm 128$ ha was dense seagrass and $355 \pm 104$ ha was sparse seagrass, according to the manually extracted data. The coefficient of variation (CV) of the overall vegetation area was low $(\leq 0.1)$ for all types of vegetation and dense vegetation, and was 0.16 for sparse vegetation (in Table 4 "Total area equal extent" refers to areas containing missing values, i.e. the deeper areas and the transition zone of the northern sub-region in any years were eliminated).

We then compared the temporal fluctuations in the seagrass area among the sub-regions based on the CV values. The shallow northern, deep middle, shallow middle, and river mouth sub-regions showed the greatest fluctuations in the area of all types of vegetation. In the shallow northern sub-region, where the highest fluctuation was observed, the area of all types of vegetation increased by more than 70\% between 1974 and 1995; however, in 2003 , it was reduced by $41 \%$, according to the manual extraction method (Table 4, Figure 4). During the same periods, all types of vegetation showed an $88 \%$ increase and a $70 \%$ decrease in the semi-automatic classification and a $49 \%$ increase and a 35\% decrease in the automatic classification. Compared to manual classification, the semi-automatic classification exhibited a greater difference each year between color and grayscale images. Unfortunately, we were unable to test whether the differences in estimated spatial extents between the methods were statistically significant, due to the limited number of images. The automatic classification had a tendency to depict more stable changes than those extracted manually. 


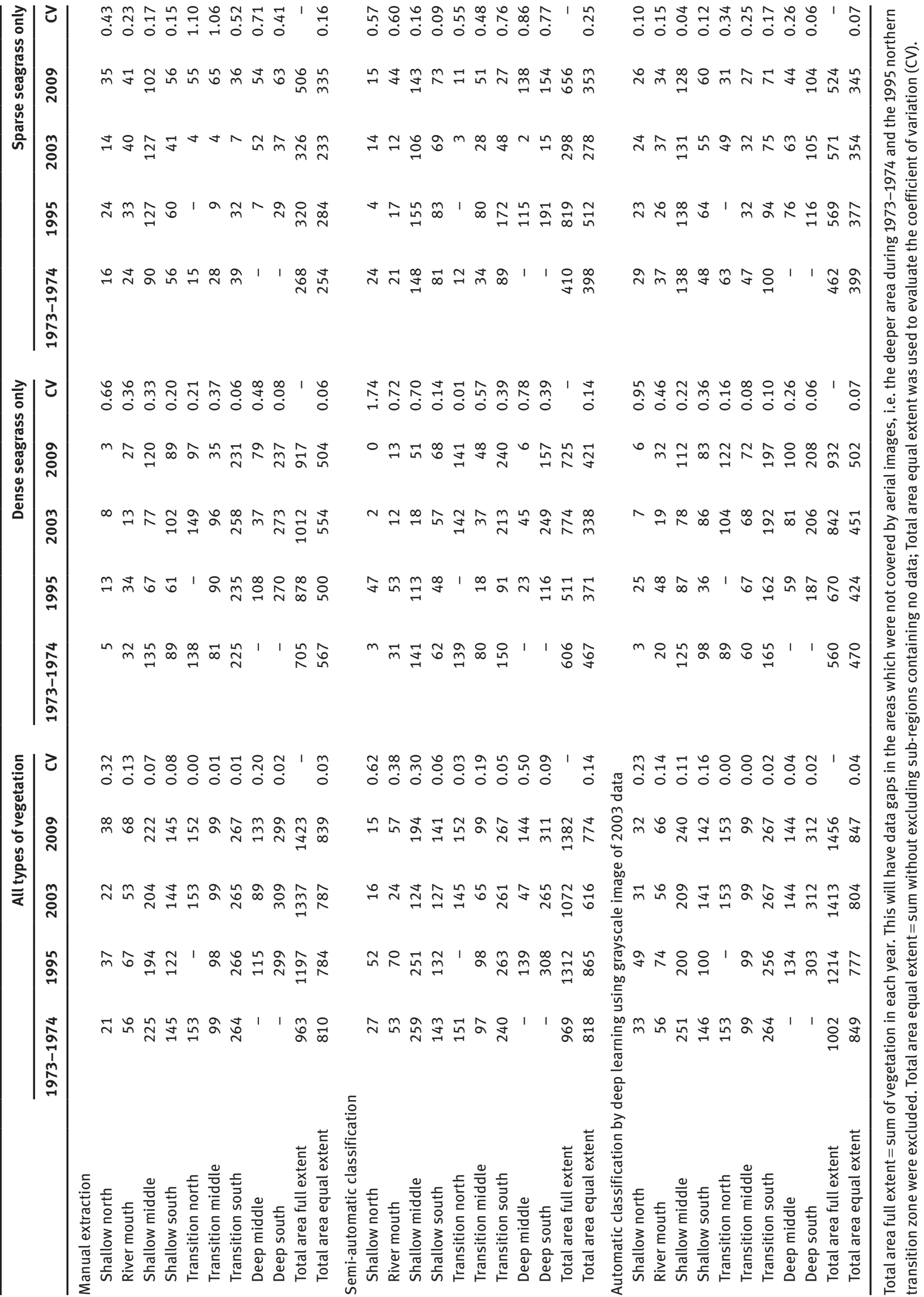




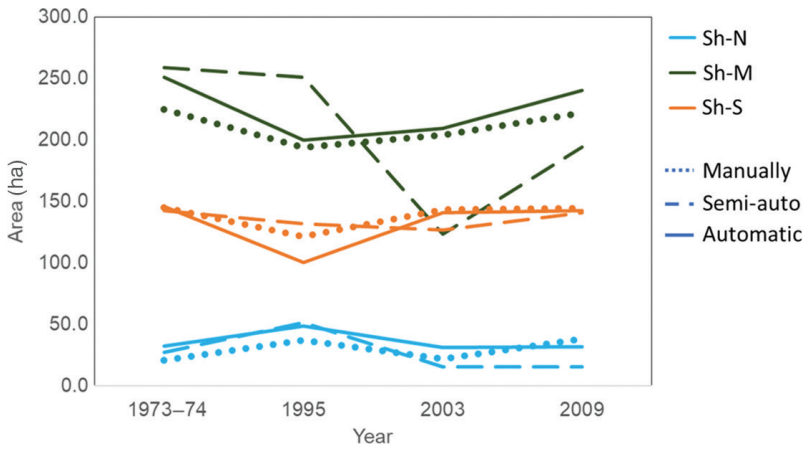

Figure 4: Temporal changes in all types of seagrass area for the three shallow (Sh) sub-regions classified using the manual, semiautomatic, and automatic (deep learning) methods (N, northern; $M$, middle; $S$, southern).

The greatest changes in area of all types of vegetation occurred in the shallow middle sub-region in 1995, with a decrease of $31 \mathrm{ha}$, and in the deep middle subregion in 2009, with an increase of 44 ha, according to manual extraction (based on the difference between 1995 and 2009, and the previous year in Table 4). As with the manual extraction, the greatest decrease in 1995 was in the shallow middle sub-region (51 ha) according to the automatic classification, but this decrease was only 8 ha in the semi-automatic classification, which may have failed the accuracy requirements of the classification in this year. Changes in the deeper area were also observed in 2009 in the semi-automatic classification, with an increase of 97 ha, but not in the automatic classification (0 ha) as shown in Table 4. Most of this change observed in the semi-automatic classification was an artifact of sunlight contamination. This difference could have been caused by the elimination of areas with sunlight contamination while making the training datasets for both types of models; however, it was not possible to eliminate all this contamination by manual tracing. Because semiautomatic classification is fundamentally based on the pixel values of images, it was closer to using the human eye in this case, whereas the automatic classification was robust to the change of the colors and captured other features not visible only by the colors.

\section{Result of the visual interpretation of images}

In this section, temporal changes in the seagrass distribution determined by visual interpretation of original images (Figure 3) are explained. Although visual interpretation and manual tracing is not perfect, it was considered to be the best method because the experts know the local area and are likely able to correctly identify the trends captured in the images. It is also appropriate to assess the detectability of local landscape structure qualitatively by comparison with the results of semi- and fully automatic classification.

In 1973 and 1974, there was relatively little seagrass in the shallow northern sub-region. In the river mouth sub-region, the routes of channels from the mouth to the deeper areas differed from those in recent images (2003 and 2009). There were two channel branches: one was a shallower channel located near those in the recent images (inside river mouth sub-region; "new river mouth" in Figure 1), and the other flowed about $1 \mathrm{~km}$ south of the recent channels and was located in the middle sub-region ("old river mouth"), where this broad and meandering channel carried sand to a wide area (especially in the shallow middle sub-region). In the shallow southern subregion, zones of dense seagrass beds were observed parallel to the coastline, and the whole area was covered by either dense or sparse vegetation. Although these spatial patterns were distinguished by manual classification, they were not clearly recognized by semi-automatic classification. The patterns spanning from the northern subregion to halfway down the middle sub-region were also recognized by the automatic classification. In addition, no images of the deeper parts could be obtained for 1973 and 1974. Few noticeable differences occurred between these years, with the detection of only a few new patches or gaps.

By 1995, in the shallow northern sub-region, seagrass beds extended across the whole sub-region. The branch of the channel flowing due west became the main channel and the former river channel on the northern side became a dense seagrass bed in the shallow middle sub-region. However, in the center of this sub-region, the dunes that flowed from the river mouth to the south spread into the shallow areas. As a result, the width of the sand bars extended to the southern side of this shallow middle subregion where dense vegetation was observed in the 1970 s. Overall, the seagrass beds occupied a narrower area in this sub-region. In the shallow southern sub-region, the shape of the seagrass beds became clearly visible, but the relative vegetation density declined. In the shallow parts of the study site, these spatial patterns were distinguished by manual classification. Although the increase of seagrass area in the northern sub-region was recognized, other features were not clearly observed by semi-automatic classification. Automatic classification reproduced these spatial distributions at low resolution (e.g. 10-m resolution). 
In the deep middle sub-region, a patchy structure was observed. This was recognized as a constricted distribution of large species that produced dense patches (looking like tussock in highland wetland), possibly mixing with the small seagrass species, which were described in a previous survey (Nakaoka and Supanwanid 2000). Manual extraction could not reliably delineate this patchy spatial pattern in the transition zone and deeper part of the study site. Although several local patches could be extracted manually, this could not be achieved across the site in equal quality. Even at low resolution, the spatial patterns in the deeper part could not be drawn because the spatial extent of the seagrass patches was too small.

By 2003, in the shallow northern sub-region, vegetation had decreased in locations close to the coast, and the seagrass remained only in the deeper zones at the boundary of the transition sub-region. The river mouth area showed changes in sand flow structures at the channel mouth. Sand flowed south and offshore from the channel, with decreased flow to the northern side. All types of classification distinguished similar changes in the spatial patterns, except in the shallow southern sub-region and the deep middle sub-region using semiautomatic classification. In the former sub-region, there were no significant changes of the spatial extent of all types and dense vegetation while others increased. and the latter sub-region was highly affected by sunlight contamination. However, the intensity of the changes differed among classification methods, as noted in the text regarding spatial changes. Especially in the case of semi-automatic classification, many of the spatial patterns were inaccurate because of the overestimation of sand area.

The 2009 images showed no major structural differences in seagrass beds from those taken in 2003; however, the density and visibility of the beds in the image differed. In the shallow northern sub-region, vegetation increased in locations close to the coast and on the boundary of the transition area. Patchy structures in deeper areas were most clearly observed in the 2009 image. Because there were no large changes in the seagrass area from 2003, the spatial patterns detectable by different classifications were also similar, except for the improved result of semi-automatic classification. Less overestimation of the sand area by semi-automatic classification in 2009 enabled that method to detect spatial patterns in the northern and middle sub-regions at a level comparable to the manually and automatically classified results. However, these three methods showed different spatial patterns in the deeper part, suggesting that automatic and semi-automatic results may not reflect the actual distribution pattern when it was applied to the deeper area in this case.

\section{Discussion}

\section{Comparison of the classification methods}

The accuracy of the image classification methods varied widely. Although they were unable to accurately distinguish between sparse and dense seagrass beds, all the methods were able to discriminate the presence or absence of seagrass with an accuracy of $80 \%$ or more. In most cases, the accuracy of the automatic classification was as good as that of semi-automatic classification. Furthermore, automatic classification did not show a decline in accuracy because of pre-conversion of the images from color to grayscale, nor was there a significant difference in accuracy between the year with supervised data (2003) and other years.

Large differences in accuracy were also observed among different types of images and mainly corresponded to their condition (i.e. color, sharpness, and contrast range), which was worse in older grayscale images. This difference in accuracy between grayscale and color images was observed with semi-automatic classification, but it was less of an issue with automatic classification. Therefore, we conclude that the automatic classification model is able to extract appropriate features to detect the presence or absence of seagrass from images with only a single grayscale band. Among the methods, automatic classification had similar or better accuracy than object-based semi-automatic classification even while using grayscale images, which are commonly used for long-term remote sensing analyses.

The advantage of automatic classification, which uses a single model pre-trained over several years, was apparent. There was no significant misfit in the temporal change of the spatial extent of seagrass beds as compared to the manually extracted spatial changes. Across the timeseries, the automatic classification extracted patterns more uniformly than supervised classification, the use of which varied depending on the year. A typical example of this advantage was also observed at the boundaries of the different images after classification in similar periods, such as the two images from the 1970s or those from 1995. In addition, the ability of the automatic classification method to detect low-resolution spatial patterns was comparable to that of manual extraction, especially at the shallow sub-regions. 
However, for evaluating fine-scale patch structures (which was not the main purpose of this study), there were distinct discontinuities between the grids used in the analysis of automatic classification. Therefore, many places were not suitable for the analysis of fine patch structures straddling the grid. Possible causes for this were the treatment of the boundary in the model or "over-fitting" to the supervised images. Pix2pix enlarges the input image once to use the boundary information in the model. During this time, information at the edge was used more than that from other areas. If the boundary contains more specific features compared to other areas, then the bias of the features will be strengthened. Because many of the artifacts occurred at a similar distance from the boundary, the result of the automatic classification may have been affected by this bias. Over-fitting means that a model fits too well to the specific supervised data, but fails to achieve high accuracy with independent test data because of less flexibility of the model (Kramer 2016). Over-fitting by GANs also tends to depend on the majority of the features in input data (Creswell et al. 2018). Because more artifacts were observed in the same direction in many areas, the strongest bias was likely to be the water depth gradient of the vegetation in the training data. Detecting the artifacts, distinguishing their cause, and properly manipulating the cause, such as boundaries or depth trends in training data, will need to be dealt with in the future. What is required is not only to build and compare different deep-learning models, but also to standardize preand post-processing of images to eliminate biases.

In addition, automatic classification requires less effort for extraction than the other methods because it requires only a single year of classified results for use as training data, while the others require supervised data for each year to ensure their accuracy. Therefore, except for machine learning time and the effect of the treatment of artifacts at the grid boundaries, which may be addressed in the near future, automatic classification can serve as a time-efficient method for extracting information related to the presence or absence of seagrass beds, especially in time-series images that are grayscale.

\section{Distribution and temporal change of the seagrass beds}

Considering the spatial changes of the seagrass in the study site, the beds were larger and denser in the deeper parts (ca. 3-4 m depth) of the study area, as reported in previous field studies (Nakaoka and Supanwanid 2000). In the deeper areas, there were patches of the large seagrass Enhalus acoroides and several smaller species. The patchy structures observed in the recent images also correspond with this characteristic of species distributions observed previously.

Marked temporal variation was observed, especially in shallow areas near the river mouth (i.e. the shallow north, shallow middle, and river mouth sub-regions) before and after 1995, when the flow of sand and the movement of the sand bars were observed in both the manually and automatically classified results. Therefore, sand dynamics are a likely driver of the distribution of shallow seagrasses, which mainly consist of smaller species. Studies describing local changes in seagrass beds noted a relationship between the change in bottom sediment and density of seagrass beds (Department of Marine and Coastal Resources 2005, Nakaoka et al. 2007). Nakaoka et al. (2007) investigated seagrass coverage and biomass changes in the Andaman Sea from 2000 to 2006. They recorded a decline in seagrass coverage in 2003 that was nearly recovered by 2006. Likewise, in this study, no major changes were observed between 2003 and 2009. Together, these observations indicate that sand movements change seagrass distributions over a relatively short time scale, making it difficult to discriminate between the magnitudes of these variations. Considering results of the current study based on remote sensing and the previous field study, seagrass beds in this relatively pristine area show stable trends and resilience to disturbance on a broad spatial scale. However, local changes, which are likely to be caused by river discharge, remained visible (as seen on the aerial photographs) for a longer time. For the conservation of the seagrass beds in this area, any modification of the river, including land cover changes in its basin, should be monitored more than other factors.

In conclusion, this comparison of multiple extraction methods revealed that automatic image transformation using deep learning can be used for quick extraction of information regarding the presence of seagrass beds. Use of the same pre-trained models was advantageous with regard to accuracy and consistency of extraction as compared to that of the semi-automatic classification method, which was affected by the condition of the images and the different models made for each image. Applying this model to images of a protected marine area from the 1970s indicated that the seagrass beds had stable spatial dynamics, with a slight decrease in area around 1995. These results matched those of the manual tracing, even in the grayscale images, which is the common type of old photographs used for long-term monitoring of seagrass populations. However, there are still challenges to be resolved, especially with regard to the discrimination of density categories and the effect of grid boundaries on image analyses. 
Acknowledgments: We thank Chittima Aryuthaka, Yaowaluk Monthum, N. Tippamas Srisombat, Suwat Pleumarom, and other staff members of Kasetsart University and the Marine National Park Education Center, Thailand, for field assistance. We also thank Khanjanapaj Lewmanomont, Chatcharee Supanwanid, Sompoch Nimsantichareon, and Isao Koike for their invaluable support in various aspects of our field research, and Norihiro Yamate, Hiroo Imaki, and members of Pacific Spatial Solutions Inc. for their technical assistance. This study was partially supported by grants from the Japan Society for the Promotion of Science (Funder Id: http://dx.doi.org/10.13039/501100001691, nos. 07J02341, 11740425, 16405007) and the Environment Research and Technology Development Fund [S-15, Predicting and Assessing Natural Capital and Ecosystem Services (PANCES)] of the Ministry of the Environment, Japan. This study is dedicated to the memory of the late Dr. Chittima Aryuthaka, who was dedicated to organizing various international programs on marine ecology in Thailand. This research could not have been conducted without her support.

\section{References}

Asaad, I., C.J. Lundquist, M.V. Erdmann and M.J. Costello. 2017. Ecological criteria to identify areas for biodiversity conservation. Biol. Conserv. 213: 309-316.

Beckham, C. and C. Pal. 2017. A step towards procedural terrain generation with GANs. arXiv preprint arXiv:1707.03383.

Campbell, J.B. and R.H. Wynne. 2011. Introduction to remote sensing. Guilford Press, NY, USA.

Chansang, H. and S. Poovachiranon. 1994. Distribution and species composition of seagrass beds along the Andaman Sea Coast of Thailand. Phuket Marine Biological Center Research Bulletin (Thailand) 59: 43-52.

Creswell, A., T. White, V. Dumoulin, K. Arulkumaran, B. Sengupta and A.A. Bharath. 2018. Generative adversarial networks: an overview. IEEE Signal Process. Mag. 35: 53-65.

Dahdouh-Guebas, F. 2002. The use of remote sensing and GIS in the sustainable management of tropical coastal ecosystems. Environ. Dev. Sustain. 4: 93-112.

Department of Marine and Coastal Resources (DMCR). 2005. Rapid assessment of the tsunami impact on marine resources in the Andaman Sea, Thailand.

Foga, S., P.L. Scaramuzza, S. Guo, Z. Zhu, R.D. Dilley, T. Beckmann, G.L. Schmidt, J.L. Dwyer, M. Joseph Hughes and B. Laue. 2017. Cloud detection algorithm comparison and validation for operational Landsat data products. Remote Sens. Environ. 194: 379-390.

Fortes, M.D., J.L.S. Ooi, Y.M. Tan, A. Prathep, J.S. Bujang and S.M. Yaakub. 2018. Seagrass in Southeast Asia: a review of status and knowledge gaps, and a road map for conservation. Bot. Mar. 61: 269-288.

Goodfellow, I.J., Y. Bengio and A. Courville. 2016. Deep learning: adaptive computation and machine learning. MIT Press, Cambridge.
Hemminga, M.A. and C.M. Duarte. 2000. Seagrass ecology. Cambridge University Press, Cambridge.

Faridah-Hanum, I., G.S. Rawat, T. Yahara, M. Abi-Said, R.T. Corlett, F. Courchamp, R. Dai, H. Freitag, T. Haryoko, C.L. Hewitt, T. Hussain, T. Kadoya, G. Maheswaran, T. Miyashita, B. Mohan Kumar, A. Mohapatra, T. Nakashizuka, J.J. Piggott, C. Raghunathan, R. Rawal, A. Sheppard, Y. Shirayama, Y. Son, N. Takamura, S. Thwin, T. Yamakita, C.M. Febria, A. Niamir. 2018. Chapter 3: Status, trends and future dynamics of biodiversity and ecosystems underpinning nature's contributions to people. In: (M. Karki, S. Senaratna Sellamuttu, S. Okayasu, W. Suzuki, eds.) The IPBES regional assessment report on biodiversity and ecosystem services for Asia and the Pacific. Secretariat of the Intergovernmental Science-Policy Platform on Biodiversity and Ecosystem Services, Bonn, Germany. pp.175-264.

Isola, P., J.-Y. Zhu, T. Zhou and A.A. Efros. 2016. Image-to-image translation with conditional adversarial networks. arXiv preprint arXiv:1611.07004.

Kawaguchi, S. and K.-I. Hayashizaki. 2011. Biodiversity studies on seaweeds and sea grasses in the coastal waters of Southeast Asia (Project-3: Seaweed/seagrass Group). Coastal Marine Science in Southeast Asia - Synthesis Report of the Core University Program of the Japan Society for the Promotion of Science: Coastal Marine Science (2001-2010), pp. 49-57.

Komatsu, T., C. Igararashi, K. Tatsukawa, M. Nakaoka, T. Hiraishi and A. Taira. 2002. Mapping of seagrass and seaweed beds using hydro-acoustic methods. Fisheries Sci. 68: 580-583.

Kramer, 0. 2016. Machine learning for evolution strategies. Springer, Heidelberg.

Landis, J.R. and G.G. Koch. 1977. The measurement of obserber agreement for categorical data. Biometrics 33: 159-174.

Lewmanomont, K., S. Deetae and V. Srimanobhas. 1996. Seagrasses of Thailand. Seagrass biology. Proceedings of an International Workshop: Rottnest Island, Western Australia. Faculty of Sciences, the University of Western Australia, Nedlands. pp. 21-26.

Lewmanomont, K., C. Supanwanid and M. Nakaoka. 2000. Species composition of seagrasses at Haad Chao Mai National Park, Trang Province, Thailand. Kasetsart Univ. Fish. Res. Bull. 22: 21-22.

Loveland, T.R., B.C. Reed, D.O. Ohlen, J.F. Brown, Z. Zhu, L. Yang and J.W. Merchant. 2000. Development of a global land cover characteristics database and IGBP DISCover from $1 \mathrm{~km}$ AVHRR data. Int. J. Remote Sens 21: 1303-1330.

Lyons, M.B., S.R. Phinn and C.M. Roelfsema. 2012. Long-term land cover and seagrass mapping using Landsat and object-based image analysis from 1972 to 2010 in the coastal environment of South East Queensland, Australia. ISPRS J. Photogramm. Remote Sens. 71: 34-46.

Lyzenga, D.R. 1978. Passive remote sensing techniques for mapping water depth and bottom features. Appl. Opt. 17: 379-383.

Lyzenga, D.R. 1981. Remote sensing of bottom reflectance and water attenuation parameters in shallow water using aircraft and Landsat data. Int. J. Remote Sens. 2: 71-82.

Matsunaga, T., A. Hoyano and Y. Mizukami. 2000. Monitoring of coral reefs on Ishigaki Island in Japan using multitemporal remote sensing data. Proc. SPIE Hyperspectral Remote Sensing of the Ocean 4154: 212-222.

Nakaoka, M. and C. Supanwanid. 2000. Quantitative estimation of the distribution and biomass of seagrass at Haad Chao Mai National Park, Trang Province, Thailand. Kasetsart Univ. Fish. Res. Bull. 22: 10-22. 
Nakaoka, M., Y. Tanaka, H. Mukai, T. Suzuki and C. Aryuthaka. 2007. Tsunami impacts on biodiversity of seagrass communities in the Andaman Sea, Thailand. (1) Seagrass abundance and diversity. Publications of the Seto Marine Biological Laboratory. Special Publication Series 8: 49-56.

Olthof, I. 2017. Mapping seasonal inundation frequency (19852016) along the St-John River, New Brunswick, Canada using the landsat archive. Remote Sens. 9: 143.

Orth, R.J., T.J.B. Carruthers, W.C. Dennison, C.M. Duarte, J.W. Fourqurean, K.L. Heck, A.R. Hughes, G.A. Kendrick, W.J. Kenworthy, S. Olyarnik, F.T. Short, M. Waycott and S.L. Williams. 2006. A global crisis for seagrass ecosystems. BioScience 56: 987.

Short, F.T., C.A. Short and A. Novak. 2018. Seagrasses. In: (C.M. Finlayson, R. Milton, C. Prentice and N.C. Davidson, eds) The Wetland book: II: distribution, description, and conservation. Springer, Dordrecht, Netherlands. pp. 73-91.

Tittensor, D.P., C. Mora, W. Jetz, H.K. Lotze, D. Ricard, E.V. Berghe and B. Worm. 2010. Global patterns and predictors of marine biodiversity across taxa. Nature 466: 1098-1101.

United Nations. 2016. The first global integrated marine assessment. United Nations.

Wabnitz, C. and S. Andréfouët. 2008. Regional-scale seagrass habitat mapping in the Wider Caribbean region using Landsat sensors: applications to conservation and ecology. Remote Sens. Environ. 112: 3455-3467.

Waycott, M., C.M. Duarte, T.J.B. Carruthers, R.J. Orth, W.C. Dennison, S. Olyarnik, A. Calladine, J.W. Fourqurean, K.L. Heck, A.R. Hughes, G.A. Kendrick, W.J. Kenworthy, F.T. Short and S.L. Williams. 2009. Accelerating loss of seagrasses across the globe threatens coastal ecosystems. Proc. Natl. Acad. Sci. USA 106: 12377-12381.

Yaakub, S.M., J. Lean, S. Ooi, P. Buapet and R. Unsworth. 2018. Seagrass research in Southeast Asia. Bot. Mar. 61: 177-179.

Yamakita, T. 2018. Change of the ocean after the Great East Japan Earthquake -Utilization of Geographic Information System and GIScience. E-Res. Spec. Biol. 2: in press. in Japanease.

Yamakita, T. 2019. Eelgrass beds and oyster farming at a lagoon before and after the Great East Japan Earthquake 2011: potential to apply deep learning at a coastal area. IGARSS 2019 IEEE International Geoscience and Remote Sensing Symposium. IEEE. in press.

Yamakita, T. and M. Nakaoka. 2009. Scale dependency in seagrass dynamics: how does the neighboring effect vary with grain of observation? Popul. Ecol. 51: 33-40.

Yamakita, T., K. Watanabe and M. Nakaoka. 2011. Asynchronous local dynamics contributes to stability of a seagrass bed in Tokyo Bay. Ecography 34: 519-528.

Yamakita, T., K. Sudo, Y. Jintsu-Uchifune, H. Yamamoto and Y. Shirayama. 2017. Identification of important marine areas using ecologically or biologically significant areas (EBSAs) criteria in the East to Southeast Asia region and comparison with existing registered areas for the purpose of conservation. Mar. Pol. 81: 273-284.

Yamakita, T., H. Yokooka, Y. Fujiwara, M. Kawato, S. Tsuchida, S. Ishibashi, T. Kurokawa and K. Fujikura. 2018. Image dataset of ophiuroid and other deep sea benthic organisms in 2015 extracted from the survey off Sanriku, Japan, by the research following the Great East Japan Earthquake 2011. Ecol. Res. 33: 285-285.

Article note: This article is related to special issue Seagrass research in Southeast Asia, published in Botanica Marina 2018, vol. 61 , issue 3 .

\section{Bionotes}

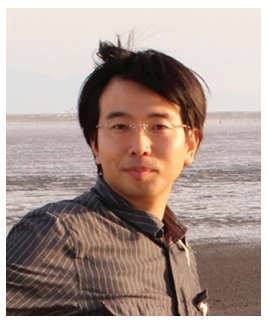

Takehisa Yamakita

Japan Agency for Marine-Earth Science and Technology, 2-15, Natsushima-cho, Yokosuka-city, Kanagawa 237-0061, Japan; Environmental Dynamics and Management Group, Graduate School of Biosphere Science, Hiroshima University, 1-3-2 Kagamiyama, Higashi-Hiroshima City, Hiroshima 739-8511, Japan; and Division of Global Environmental Studies, Sophia University, 7-1 Kioicho, Chiyoda-ku, Tokyo 102-8554, Japan yamakitat@jamstec.go.jp https://orcid.org/0000-0002-5451-1231

Takehisa Yamakita is a spatial ecologist at JAMSTEC. He was awarded a PhD by Chiba University for research on spatial dynamics of seagrass. As a postdoctoral researcher at the University of Tokyo, he began work to predict marine biodiversity over Japan and Asia to support conservation policy. Recently, he has worked as a sub-leader of the marine group in a project S-15; PANCES, as lead author of an IPBES Regional Assessment, as a unit sub-leader of tsunami assessment in Tohoku Ecosystem-Associated Marine Sciences (TEAMS). He also had lectures as an associate professor at Hiroshima University and a lecturer at Sophia University.

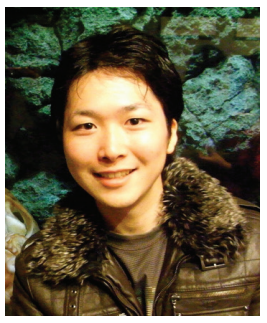

Fumiaki Sodeyama

Japan Agency for Marine-Earth Science and Technology, 2-15, Natsushima-cho, Yokosuka-city, Kanagawa 237-0061, Japan

Fumiaki Sodeyama is a technical assistant staff at JAMSTEC and serves as an adjunct instructor/lecturer at Urawa University. He earned a master's degree in developmental biology at the University of Tokyo. As a researcher at Misaki Marine Biological Station, he studied the life history and distribution of the feather star, including a genetic survey across Japan. He is currently working in the marine group of S-15 (Predicting and Assessing Natural Capital and Ecosystem Services) and testing several deep learning techniques.

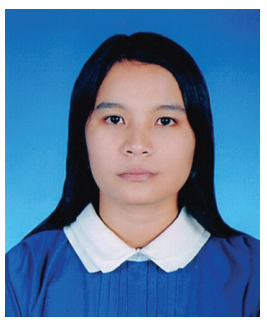

Napakhwan Whanpetch

Department of Marine Science, Faculty of Fisheries, Kasetsart University, 50 Ngam Wong Wan Road, Ladyao Chatuchak, Bangkok 10900, Thailand

Napakhwan Whanpetch is a marine ecologist at Kasetsart University. She was awarded a PhD by Chiba University for research on the variation of macrobenthic invertebrate communities in seagrass. She started her professional research career in the Department of Marine Science, Faculty of Fisheries, Kasetsart University, where 
she now serves as a lecturer and the Assistant Dean for Academic Affairs. She is part of the research program that monitors the impact on the Andaman Sea of the 2004 Indian Ocean earthquake and tsunami, as well as the program researching marine ecosystems at the Andaman Coastal Research Station for Development, Ranong Province, and adjacent areas.

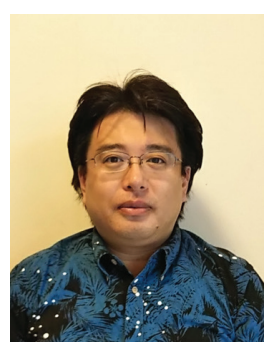

\section{Kentaro Watanabe}

Waterfront Vitalization and Environment Research Foundation, 405, Malissa Hills, 176-4, Asato, Naha, Okinawa 902-0067, Japan

Kentaro Watanabe is a researcher at the Waterfront Vitalization and Environment Research Foundation. He earned his master's degree at the Marine Ecology Lab of Hokkaido University and studied the spatio-temporal variation of seagrass and seaweed using remote sensing, databases, and GIS at the Akkeshi Marine Station, Field Science Center for Northern Biosphere, Hokkaido University.

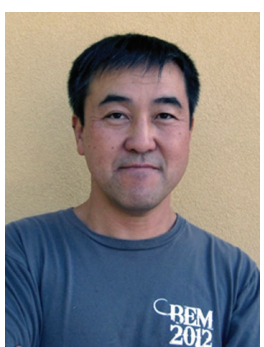

\section{Masahiro Nakaoka}

Akkeshi Marine Station, Field Science Center for Northern Biosphere, Hokkaido University, Aikappu 1, Akkeshi, Hokkaido 088-1113, Japan. https://orcid.org/0000-0002-57223585

Masahiro Nakaoka is a professor at Hokkaido University and the Director of the Akkeshi Marine Station, Field Science Center for Northern Biosphere, Hokkaido University. He completed his PhD and undergraduate studies at the University of Tokyo. His marine ecology research ranges from basic subjects like plant-animal interactions in seagrass beds to more applied topics like evaluating multiple ecosystem services of coastal ecosystems in Asia. He collaborates with researchers from other countries, using the Akkeshi Marine Station as a base for international research networks, including ZEN (Zostera Experimental Network), GAME (Global Approach by Modular Experiments) and TSUNAGARI (Belmont Forum-funded international project). 


\section{Graphical abstract}

Takehisa Yamakita, Fumiaki Sodeyama, Napakhwan Whanpetch, Kentaro Watanabe and Masahiro Nakaoka

Application of deep learning techniques for determining the spatial extent and classification of seagrass beds, Trang, Thailand

https://doi.org/10.1515/bot-2018-0017

Botanica Marina 2019; 62(4):291-308
Research article: A deep learning model determined seagrass extent using grayscale aerial photographs. Vegetation recognition accuracy (>80\%) was as high as monochrome

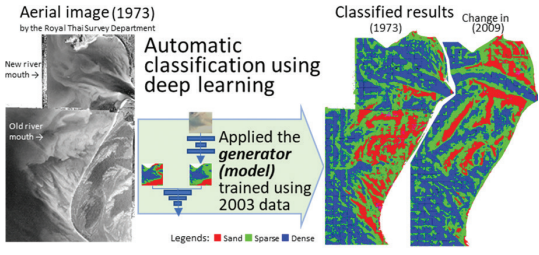
remote sensing. Landscape structures preserved in classified images enabled detection of changes in patches at the river mouth.

Keywords: Andaman Sea; deep learning; land cover classification; long-term dynamics; remote sensing. 